\title{
The Role of Authentic School Leaders in Promoting Teachers' Well-Being: Perceptions of Israeli Teachers
}

\author{
By Yaffa Buskila ${ }^{+} \&$ Tamar Chen-Levi*
}

\begin{abstract}
This study aims to explore teachers' perceptions of the role played by school principals in promoting teachers' well-being. The teachers in Israel have a low professional self-image and work under stressful conditions. Psychological wellbeing combines a good feeling with effective functioning and promoting wellbeing can enhance efficacy at work. This is a qualitative study, with a personal interpretive paradigm of teachers' reflections. Data was collected from 53 teachers and analyzed in a four-stage process: condensing, coding, categorizing, and theorizing. The study was based on the planned theory (Ajzen \& Fishbein, 1980), and the data was encoded and categorized according to the Goleman, Boyatzis and McKee (2004) emotional intelligence (EI), leadership competence which founds to enhance well-being and effectiveness at work. Findings indicate that school principals can play an important role in promoting teachers' wellbeing by displaying relationship management, which generates the highest level of EI: Creating a positive emotional climate, keeping relationships on the right track, and demonstrating genuine concern for teachers. Understanding the importance of EI and mastering it by educational leaders is important for promoting well-being. It is significant for the positive functioning of the teachers and school system. This study contributes to the epistemology of promoting teachers' well-being and developing EI by educational leader.
\end{abstract}

Keywords: School principals, teachers' well-being, emotional intelligence

\section{Introduction}

The teaching profession is considered to be highly stressful in many places in the world (Jepson \& Forrest, 2006) and in Israel as well. There are many reasons for this stress but one of the prominent ones is the neoliberal ideology that advocated for competition, accountability, equality and more (Carnoy, 1995). Stress is a negative phenomenon that develops under conditions of uncontrollable, prolonged and increased pressure. It is defined as a psychological and emotional reaction to imbalance between requirements and the ability to fulfill them (Hakanen, Bakker, \& Schaufeli, 2006). It has side effects in terms of health, adverse results at work, and the reduction of job satisfaction (Bellingrath, Weigl, \&Kudielka, 2008). In Israel, the stressful conditions affect the whole education system and cause teachers and school principals to leave the profession (Oplatka, 2017), further exacerbating the situations. There is a shortage of 3,000 teachers in the Israeli education system due to stress and burnout (Datal, 2019). This scarcity of teachers is not only an Israeli problem; it exists in many other places as well

\footnotetext{
${ }^{+}$Lecturer, Orot Israel College of Education, Rehovot, Israel.

*Lecturer, Department of Education, Bar-Ilan University, Ramat Gan, Israel.
} 
such as England, Switzerland, Scotland, Australia, New Zealand, USA and Germany (Shnider Levi, 2016), and even in East Asia (Bas, 2011).

Stress has a negative effect on the well-being of individuals and on the organization as a whole (O'Driscoll \& Cooper, 1996). The World Health Organization (WHO) has defined positive mental health as "a state of Well-being which the individual realizes his or her own abilities, can cope with the normal stresses of life, can work productively and fruitfully and is able to make contributions to his or her community" (WHO, 2001).

Ajzen \& Fishbein (1980) developed a planned behavior theory that reveals strong connections between perceptions, attitude and behavior. Recent studies have proven the significance of value-based leadership, through the concept of authentic leadership. Authentic leaders are among the prominent kinds of school leaders that is considering attitude and traits that affects behavior. Authentic leadership is defined as leadership which promotes a positive attitude as well as moral and ethical perspectives, and is positively related to organizational outcomes such as job satisfaction and work performance (Bird, Wang, Watson \& Murray, 2009; Shapira-Lishchinski \& Tzemach, 2014).

However, little research has been conducted on the role of authentic leaders in promoting teachers' well-being in the era of neoliberal reforms and on how this is actually done. There is also very little research on how leaders' behavior affects teachers' emotional processes (Cliffe, 2011). Israel is an interesting case to study in this context, because like many other countries in the world it is taking part in the neoliberal reforms, however, despite the huge efforts it has made in the hope of improving the educational system (Berkovich, 2014) - it has had no success. It is interesting to study teachers' perspectives since they are those who stand in the frontline and are required to work under stressful conditions (Oplatka, 2017). Thus, we believe that they know better than others what is good for them and what their perceptions are concerning the role of school principals in promoting their well-being at work.

The purpose of our study is to construct a new body of knowledge compiled from teachers in Israel on how they perceive the role of school principals as promoting their well-being. Our research question is: What are teachers' perceptions regarding the role of school principals in promoting teachers' wellbeing, and how is this to be done?

Since stress, which is a psychological and emotional reaction (Hakanen, Bakker, \& Schaufeli, 2006), can be managed by developing well-being, we will connect the planned theory of Ajzen \& Fishbain (1980) for predicting authentic leaders' behavior toward teachers to theories that have reported on developing well-being through emotional and social aspects of leaders' behavior (Brotheridge \& Lee, 2008). 


\section{Literature Review}

\section{Stress in the Teaching Profession}

There is growing evidence indicating that the teaching profession is stressful (Jepson \& Forrest, 2006). In Israel it is even considered to be highly stressful for many reasons, among which are the neoliberal ideology of economy competition, accountability, and equality (Carnoy, 1995), as well as other demands that have evolved over recent years (Oplatka, 2017). All these factors, together with the pressure to improve students' achievements (Bogler \& Nir, 2014), have pushed Israeli policymakers to suggest the recent educational reforms Ofek Chadash ("New Horizon") and Oz LaTmura ("The Courage to Change"). These reforms have increased stress in the whole education system in Israel and on teachers as well, provoking negative emotions and responses. Teachers are also required to give in written reports on varied issues on a daily basis, which burdens them with additional stress, causing them much frustration and making them feel like clerks (Schechter, 2015). They complain about the scarcity of breaks between lessons, working under poor physical conditions and also working long hours compared to the number of hours they used to work before. They are also expected to work from home for the benefit of the school, thus arousing conflict between work demands and family demands (Buskila \& Chen Levi, 2020).

These stressful conditions affect the whole Israeli education systems and cause teachers and school principals to leave the profession (Oplatka, 2017). In May 2019 the Israeli State Comptroller Report published the fact that there is a shortage of 3,000 teachers in the country (Datal, 2019). Scarcity of teachers due to stress is not an exclusively Israeli problem: in England the teaching profession stands highest on the list of stressful professions. In Switzerland, Scotland, Australia and New Zealand, about $80 \%$ of teachers suffer from work overload. In Israel, USA and Germany, about 50\% of teachers leave the profession after 5 years (Shnider Levi, 2016), and in East Asia as well teachers leave the profession due to pressure and burnout (Bas, 2011).

Stress is a negative phenomenon that develops under conditions of uncontrollable, prolonged and increased pressure. Stress may affect health adversely, affecting work results as well (Bellingrath et al., 2009). It leads to emotional exhaustion which diminishes productivity and damages effectiveness (Niessen, Mader \& Jimmieson, 2017) as well as the quality of teaching (Cherniss, 1980). It also reduces job satisfaction, lowers occupational commitment, results in early burnout (Jepson \& Forrest, 2006) and increases job turnover (Jackson, Swab $\&$ Schuler, 1986). Stress may lead to reduced staff retention and to absenteeism, causing the school additional expenses due to having to pay replacement staff. Stress also has a negative impact on the well-being of individuals and of the organization as a whole (O'Driscoll \& Cooper, 1996). 


\section{Theoretical Framework - The Planned Behavior Theory}

Various theoretical frameworks have been proposed to deal with the psychological processes involved in the attempt to predict and explain human behavior (Ajzen, 1991). Ajzen has found that cognitive self-regulation plays a key role in predicting behavior in organizations or with respect to someone. Together with Fishbein, he developed the planned theory, which is a theory designed to predict and explain human behavior. This theory assumes that human behavior results from cognitive processes, and the "central factor in the planned theory is the individual's intention to perform a given behavior that influences" (Ajzen \& Fishbein, 1980, p. 181). This intention will determine the behavior that will be carried out. According to this theory, school principals' perceptions are connected to their attitudes, and these connections can affect their behavior, which in turn will affect teachers. For example, principals' negative perceptions will lead to negative attitudes and behaviors toward teachers. They can lead to negative feelings giving rise to a mode of functioning that will create stress (Anary, 2011); and on the other hand, school principals' positive perceptions will lead to positive attitudes and behaviors toward teachers.

\section{Authentic Leadership}

The authentic leadership construct has evolved from the positive psychology of leadership forms (Seligman, 2002), which consists of integrity, caring and an ethical attitude toward followers (Avolio \& Luthans, 2006). Authentic leadership has been defined a "process that draws form both psychological capacities and highly developed organizational context, which results in both greater selfawareness and self-regulated positive behavior on the part of leaders and associates, fostering positive self-development" (Luthans \& Avolio, 2003, p. 243). These researchers later fine-tuned their authentic leadership concept by focusing more closely on the core of self-awareness and self-regulation. While the self-regulation process includes internal regulation, balanced processing of information, interpersonal transparency and authentic behavior, authentic leadership also includes high ethical standards, which influence decision-making and behavior in general (Avolio \& Gardner, 2005).

Authentic leadership in education is a combination of values, ethics and moral literacy as applied for leadership development in all school aspects for the best interest of students. It is conceptualized through varied perspectives of psychology, philosophy, critical theory and law (Begley \& Stefkovich, 2007). Authentic leaders reflect on their own inner characteristics such as: (a) Self-awareness regarding their lives and work, their strengths and weaknesses, how others perceive them, and the impact that they have on others; (b) Trust toward others and implementation of transparency, sharing thoughts and feelings with others, and minimizing inappropriate emotions; (c) Ability for objective analysis of data, while being interested in hearing others and taking their opinions into consideration; And (d) High internal moral values combined with the expectation that others practice high moral and ethical standards as well (Bird et al., 2009). These traits 
help authentic leaders to overcome obstacles and difficulties and to solve problem (Leroy, Palanski \& Simons, 2011).

\section{Well-Being}

Well-being is the combination of feeling good and functioning effectively. It is associated with positive emotions, relatively high levels of happiness, and life satisfaction (Huppert, 2009). In the school context, well-being refers to the outcome of a process of acquiring a set of skills to recognize and manage emotions, set and achieve positive goals, appreciate others' perspectives, establish and maintain positive relationships, make responsible decisions, and handle interpersonal situations constructively (Barry, Clarke, \& Dowling, 2017). The promotion of teachers' well-being by school principals plays an important role in enabling teachers to engage in their work effectively (Brotheridge \& Lee, 2008), with higher levels of confidence and commitment (Anari, 2011), as well as assisting them in coping with stress. Elevated well-being also increases job satisfaction, productivity and successful outcomes at school (Durlak, Wiesberg, Dymnici, Tailore E Schellinger, 2011). It reduces absenteeism due to stress-related illnesses, saves money, and presents a more positive image of the profession. It also improves retention of staff and facilitates their recruitment (Jepson \& Forrest, 2006).

In the past there were recommendations to reduce stress through varied means such as: role rotation, changes in the subject-matter to be taught (Friedman\& Kampar, 1994), use of techniques such as time managements or psychological tips that can assist teachers in learning how to deal with stress. Important as these methods were, proof of their efficiency is still rare (Schnider Levi, 2016). Wellbeing was found to be negatively associated with work-family conflict and burnout (Hung, Li, Fang \& Tang, 2019). So, reducing teachers' stress by promoting their well-being is of utmost importance (Montgomery \& Rupp, 2005). Teachers' emotional well-being in school promotes the development of five interrelated sets of cognitive, and behavioral competencies: Self-awareness, self-management, social awareness, relationship skills, and responsible decision-making (Durlak et al., 2015). These competencies were understood by Goleman et al. (2004) as emotional intelligence (EI) competencies.

\section{Emotional Intelligence}

Emotional intelligence (EI) has varied definitions. The term was coined by Salovey \& Mayer who defined EI as "relevant to the accurate appraisal and expression of emotion in oneself and in others, the effective regulation of emotion in self and others, and the use of feeling to motivate, plan, and achieve in one's life" (Salovey and Mayer, 1990, p. 185). Based on the theory that cognitive capabilities are influenced by emotions (Gorge, 2000), Salovey and Mayer claim that emotions and feelings work together. EI is also evident in leadership competencies of primal leaders who excel in the art of relationships, and there are 
many evident ratings the leadership effectiveness through EI (Keer, Garvin, Heaton \& Boyle, 2005).

Goleman et al. (2004) have defined leadership in interpersonal terms and argued that the best focal point for contemplating it is through a set of social skills which can be organized in four clusters and 18 sub-scales: (1) Self-awareness which consists of three sub-scales: self-awareness, accurate self-assessment, and self-confidence; (2) Self-management which consists of six sub-scales: selfcontrol, transparency, adaptability, achievement, initiative and optimism; (3) Social awareness with three sub-competencies: empathy, organizational awareness and service orientation; (4) Relationship-management with five sub-competencies: inspiration, influence, developing others, change catalyst, conflict management, and ability to participate in teamwork and collaboration. Leaders who present these characteristics are able to generate an atmosphere of friendly collegiality and constitute models inspiring respect, helpfulness and cooperation. They draw others into active enthusiastic commitment to the collective effort and build spirit and identity.

All emotional competencies involve some degree of skill in the realm of feelings (Goleman et al., 2004). Emotions are part of each of us and they affect our every conversation, activity and decision (Bradbarry\& Greaves, 2005). They play a critical role in developing and maintaining social relationships. While intellectual capability is the pre-eminent predictor for individual work performance, group performance is more dependent on emotional competencies than on intellectual ones (Ashkanazy \& Dorris, 2017).

\section{The Emotional Role of the School Principal}

Schools are emotional institutions, and emotions play an integral part in most of the processes occurring at school such as teaching, learning and managing (James \& Vince, 2001). However, most principals give priority to administrative work (Grissom, Loeb \& Mitani, 2013) over the interpersonal aspect of school life (Harris, 2002). Recently there is growing recognition of the emotional role of leaders, and of its effect on followers' behavior (Ashkanasy \& Dorris, 2017).

School principals are expected to nurture positive relationships as well as managing their own emotions and those of their employees (Brotheridge \& Lee, 2008). They are also expected to develop sensitivity to the emotional side of school management (Fullan, 1998). Part of nurturing positive emotions is done by being emotionally expressive. School principals who are more emotionally expressive are more charismatic, more likely to generate a positive emotional climate, and better at understanding others' emotions (Oplatka, 2011; Riggio, 2007). Understanding emotions can make people more satisfied, more socially engaged and more productive. Happier people have more social contacts. They give and receive emotional support, which are associated with relatively high levels of psychological well-being (Huppert, 2009). Emotional climate at school includes also emotional vocabulary utilization and has a positive effect on emotional regulation (Berkovich \& Eyal, 2016; Clark, Hype-Hailey \& Kellinher, 2007). It tends to stimulate positive emotions in followers (Bass \& Avolio, 1994) 
and has beneficial effects on the way people perceive and interpret social behavior, as well as on how they initiate social interaction. According to Forgas (2006), people experiencing positive emotions evaluate themselves and others more positively, are more lenient, more confident, more optimistic and more generous in interpersonal situations. Positive emotions also motivate followers to transcend their own personal goals for the interests of the students in the school (Begley \& Stefkovich, 2007).

Thus, we believe that promoting teachers' well-being through developing dimensions of EI can help them to reduce their stress levels or at least to balance stress and bring it to a somewhat normal level. Emotional and social aspects of leaders' behavior might be crucial for individuals to thrive under conditions of moderate levels of emotional exhaustion (Niessen et al., 2017). They have an indirect effect on teachers' emotional reframing of various situations and were also found to provide emotional support to teachers as they enable them to reduce stress which they experience at work (Berkovich \& Eyal, 2017).

\section{Methodology}

This qualitative research comprises a personal interpretive paradigm of teachers' reflections on the role of principals in promoting teachers' well-being in Israel. The value of self-reflection contains experience, cognition and selfunderstanding, which involve emotions. "No laws, structures or mechanisms offer higher explanatory principles or greater predictive power than self-interpretations" (Crotty 2003, p. 60). The present study is designed to provide teachers' rich textual self-descriptions in order to learn more about how they perceive the role of school principals in contributing to teachers' well-being. Maximizing the depth and richness of the data and enlarging the sampling can provide us with a broader perspective (Merriam, 2009).

Participants - The 53 participants were Israeli school teachers who are studying for MA degrees in educational leadership as a prerequisite for being accepted to Avney Rosha, the Israeli Institute for School Leadership. All of these teachers are currently teaching in the public education system and studying at two big colleges in central Israel. Among participants there were 41 Jews and 12 Muslims, 7 of whom were males and 46 who were females, with at least three years of teaching experience. We are seeking to develop new knowledge derived from teachers' perceptions, rather than from school principals, because they are the firsthand sources for this knowledge. As aforementioned, they are those who stand in the front line to deal with the stressful day-to-day school life, and they know better than anyone else what is good for them, what they need and what they expect from their school principal in order to do a better job.

Data gathering-For one of the assignments in the educational leadership course, participants were asked to write self-reflections about their perception of school principals in promoting teachers' well-being. They were asked to describe their perceptions in rich detail, to explain why and how they developed them, and to bring varied examples of their own and their colleagues' experiences in different 
work situations. Participants used a questionnaire guide which instructed them to focus on key questions and sub-questions in order to elaborate on their ideas (Merrian, 2009). Participants had three months to pay attention to and follow up on situations that came up at school between them or their colleague and the school principal. The goal was to discover situations that promote well-being, to describe them in writing, and finally to formulate them into a self-report. All students submitted self-reports with their own perceptions. We informed them that we would use their insights and reflections for research purposes only. In order to maintain confidentiality, their names were changed to pseudonyms.

Data analysis - We translated the data from Hebrew to English and analyzed it in a four-stage process: condensing, coding, categorizing and theorizing. The coding guided us to identify ideas or thematic frameworks from the text which were derived from teachers in order to discover useful information. This information was sorted into meaning units that categorized and classified the material according to the features it represented. In order to construct new knowledge from teachers' perceptions about the role of school principals in promoting teachers' well-being, we took the themes that teachers attributed to school principals as imperative for promoting teachers' well-being, and classified them according to the meaning that Goleman et al. (2004) constructed and described for EI as a primal leadership competence.

\section{Results}

According to perceptions who articulated their thoughts in self-reports, school principals have an important role in promoting teachers' well-being. Thirty teachers out of 53 participants, opined that the role of school principals contains emotional components and 12 argued that emotions, either negative or positive, are contagious. They argued that school principals have to master and demonstrate 47 behaviors, most of which are part of the EI construct formulated by Goleman et al. (2004) as leadership competencies of "Primal Leadership". These EI construct is organized with primary titles, categorized into four clusters: self-awareness, selfmanagement, social awareness and relationship management, and 18 subtitles (pp. 253-256). The authors of this study organized the clusters and competences in a table and embedded in it statements or behaviors that evolved from the selfreports, which the participants related to school principal as promoting teachers' well-being. The number next to each statement notes how many teachers opined it. 
Table 1. School Principals' Behavior that Creates Well-Being

\begin{tabular}{|c|c|c|c|}
\hline Self-Awareness & Self-Management & $\begin{array}{l}\text { Social } \\
\text { Awareness }\end{array}$ & $\begin{array}{l}\text { Relationship } \\
\text { Management }\end{array}$ \\
\hline $\begin{array}{l}\text { Emotional Self- } \\
\text { awareness } \\
\text { Guiding values - } 4\end{array}$ & $\begin{array}{l}\text { Self-Control } \\
\text { 1. Restraint - } 1 \\
\text { 2. Humor - } 2 \\
\text { 3. Authoritative - } 1 \\
\text { 4. Patience - } 2 \\
\text { 5. Being calm - } 1\end{array}$ & $\begin{array}{l}\text { Empathy } \\
\text { 1. Listener }-27 \\
\text { 2. Empathy }-8 \\
\text { 3. Inclusion }-11 \\
\text { 4. Respect others } \\
-6 \\
\text { 5. Sensitive - } 2 \\
\text { 6. Keep equality } \\
\text { and justice }-6\end{array}$ & $\begin{array}{l}\text { Inspiration } \\
\text { Role model - } 12\end{array}$ \\
\hline $\begin{array}{l}\begin{array}{l}\text { Accurate Self- } \\
\text { Assessment }\end{array} \\
\text { 1. Fair and reliable - } 5 \\
\text { 2. Responsible - } 1\end{array}$ & $\begin{array}{l}\text { Transparency } \\
\text { 1. Transparency - } 2\end{array}$ & $\begin{array}{l}\text { Organizational } \\
\text { Awareness } \\
\text { 1. Freedom of } \\
\text { expression - } 17 \\
\text { 2. Bestow } \\
\text { confidence and } \\
\text { stay calm - } 4 \\
\end{array}$ & $\begin{array}{l}\text { Influence } \\
\text { 1. Delegate Authority - } \\
11 \\
\text { See others positively \& } \\
\text { believe in teachers' ability } \\
\text { \& motivation - } 31 \\
\end{array}$ \\
\hline \multirow[t]{4}{*}{$\begin{array}{l}\text { Self-Confidence } \\
\text { 1.Affable - } 4 \\
\text { 2.Patient - } 2 \\
\text { 3.Self-confidence - } 1\end{array}$} & Adaptability & $\begin{array}{l}\text { Service } \\
\text { 1. Protective, } \\
\text { caring and } \\
\text { treating fairly - } \\
38 \\
\text { 2. Help, support } \\
\text { backup } \\
\text { teachers - } 27 \\
\text { 3. Available, } \\
\text { presence } \\
\text { accessible - } 8 \\
\text { 4. Attune } \\
\text { teachers' needs } \\
\text { \& assuring } \\
\text { having } \\
\text { resources - } 17\end{array}$ & $\begin{array}{l}\text { Developing Others } \\
\text { 1. Constructive feedback - } \\
19 \\
\text { 2. Reinforce \& appreciate } \\
\text { teachers work \& } \\
\text { cultivate teachers' } \\
\text { ability -46 } \\
\text { 3. Encourage Learning -16 }\end{array}$ \\
\hline & $\begin{array}{l}\text { Achievement } \\
\text { Achievers - } 1 \\
\text { Life Long learner - } \\
14\end{array}$ & & $\begin{array}{l}\text { Change Catalyst } \\
\text { 1. Overcome barrier \& } \\
\text { solve problems - } 7\end{array}$ \\
\hline & $\begin{array}{l}\text { Initiative } \\
\text { 1. Create challenges } \\
\text { and renewing - } 6\end{array}$ & & $\begin{array}{l}\text { Conflict Management } \\
\text { 1. Understand others - } 5 \\
\text { 2. Shared decision- } \\
\text { making } 13 \\
\text { 3. Create borders \& } \\
\text { authoritative - } 4\end{array}$ \\
\hline & Optimism & & $\begin{array}{ll}\text { Teamwork and } \\
\text { Collaboration } \\
\text { 1. } \\
\text { Good relationships - } \\
20 \\
\text { 2. } \\
\begin{array}{l}\text { Democrat \& bestow } \\
\text { autonomy - } 22\end{array} \\
\text { 3. } & \begin{array}{l}\text { Generate positive } \\
\text { atmosphere \& keep } \\
\text { relationship on right } \\
\text { track - } 39\end{array} \\
\end{array}$ \\
\hline
\end{tabular}




\begin{tabular}{|l|l|l|}
\hline & & $\begin{array}{l}\text { Comfortable with } \\
\text { principal - 9 }\end{array}$ \\
& & 5. Involved - 5 \\
6. $\begin{array}{l}\text { Develop sense of } \\
\text { belonging - 12 } \\
\text { collaboration } \\
\text { teamwork \& team } \\
\text { consolidation - 26 }\end{array}$ \\
\end{tabular}

The table is based on the Golman, Boyatzis and McKEE (2004, pp. 253 256) emotional intelligence - leadership competence that was organized by the authors in a chart with primary and secondary titles. Under each title, are embedded competences that teachers attributed to school principals as promoters of well-being. The number of teachers who believe that this competence is important to promote well-being is included.

Table 1 demonstrates the teachers' self-reports articulating their answers about the imperative behaviors of school principals for promoting teachers' wellbeing. The teachers wrote 575 statements describing school principals' expected behaviors. These statements were divided by the authors into 47 sub-titles of Goleman et al. (2004). As can be seen from Table 1, the largest number of selfreports that teachers noted as important falls into the cluster of relationship management which contains 356 statements. The second-highest number of teachers' statements related to school principals' behaviors that express the social awareness cluster, with 171 statements. The third-highest number of teachers' statements related to school principals' behaviors from the self-management cluster with 31 statements. The least behaviors that school teachers relate to principals belong to the self-awareness cluster with 17 statements. Although the voice of each individual teacher is important, we will focus only on competencies mentioned by at least 15 or more teachers, such as social awareness and relationship management.

\section{Promoting Well-being through Social Awareness}

The social awareness cluster contains the ability to be empathetic and to have organizational awareness and a service orientation. There were 60 statements found in the self-reports advocating for the importance of being empathetic: The importance of being a good listener, which is an expression of empathy, was advocated by 27 teachers. For example, Mary, Shellie and Lev claimed that for a principal to be a good listener is important, and Avi added: "Principals must listen to teachers and students in school and care about them."

Twenty-one teachers talked about the importance of being organizationallyaware, and 17 teachers talked about principals who allow freedom of expression which is a part of organizational awareness: Ronnie said, "Being able to have an 
open conversation, allow teachers to talk openly about everything, without criticizing them..." Nava added, "There is a need to develop a culture of dialogue... to encourage open discussions among teachers." Rosa posited: "Freedom of expression can create cohesion among everyone and lead to good decisionmaking."

A school principal who is service-oriented was recommended by 19 teachers. Thirty-eight teachers felt that protecting followers, caring about them and treating them fairly, which all belong to the category of being service-oriented, are important: Bar said: "Being an attentive listener and a caring principal is important." Weiss argued that he would like to work with a principal who is "supportive, human and liberal"; and Robby said that principals should "make it known to teachers that their decisions will be supported." Seventeen teachers felt that principals' being attuned to teachers' needs and assuring that they have all the resources they need to perform their jobs properly are significant factors. Ayala related: "The principal's role is to take care of teachers' needs... and assure that they feel comfortable." Dana added that principals "need to take care of professional and personal needs." Shellie expected school principals to understand that "if I can't come to school one day, that means that I have a problem and I am not trying to avoid coming to work."

\section{Promoting Well-being through Relationship Management}

The main competencies that teachers viewed as essential for promoting teachers' well-being belonged to the cluster of relationship management. In this cluster, there were 356 statements. Thirty-one teachers talked about viewing teachers positively, motivating them, and believing in their abilities as important for promoting their well-being; According to Merry, "principals should develop competencies and believe in workers' abilities." Nava said: "Principals have to believe in teachers' professional ability" and Rosa said, "A good principal is one who can motivate teachers."

Developing others is also a competency that belongs to the relationship management cluster. According to 19 teachers, one of the ways to help teachers grow is by offering them constructive and professional feedback. Tal warns against "giving thoughtless feedback" because it "hurts and creates negative emotions." Another 46 statements reflected the importance of appreciating teachers' work and nurturing their abilities. For example, Chava said, "Teachers have to feel that their work is appreciated." Shira added: "I need to feel appreciated and to hear a good word about my work", and Rosa posited that "Good principals should express supportive feedback and provide recognition for good work". Both Avi and Yafit confirmed that they too believe that "Principals have to believe in teachers" capabilities". Another way to promote teachers' well-being is through encouraging the staff's learning and development: Sara commented: "Learning from others and from their successes is helpful." Also, Shai talked about the importance of "peer learning", and Sam mentioned holding "workshops and training sessions".

Teamwork and collaboration are the most significant components demonstrating the mastering of EI and they were mentioned by teachers as 
promoting their well-being. Twenty teachers talked about the importance of having good relationships with other teachers and school workers: Edi said, "School principals must recognize the importance of good relationships with teachers as an important basis for improving teacher-student relationships and as a key factor for improving teaching and learning." Mary adds that "Teachers generate positive feelings when they are treated warmly by the school principal, and Avi argued that principals must treat teachers "with sensitivity, and maintain good relationships $[\ldots]$ for improving motivation. Twenty-two teachers claimed that teamwork and collaboration are possible only when a democratic atmosphere exists at school and teachers have autonomy at work. Chen and Gila argue that school principals cannot be dictators. As for autonomy, Dana claimed, "Principals who give teachers full autonomy and trust empower them". According to Dekel, "Principals who encourage autonomy and freedom pave the way to good school citizenship".

Generating a positive atmosphere and keeping relationships on a positive track was said to be important by 39 teachers. Twenty-six teachers claimed that collaboration, teamwork and team cohesion are important. According to Miri: "Team cohesion is the school principal's responsibility. It strengthens the teachers' sense of belonging which is so important." Lev spoke about how "cohesion helps in developing an atmosphere of cooperation and team work", Avi added, "Team cohesion can create a sense of self-worth and autonomy". An additional way to develop teamwork and collaboration, through fostering a positive emotional climate, as was reported by 32 teachers, who also explained that school principals should recognize emotions, influence the school's emotional climate, and make time for discussing emotions. According to Edi, principals should "use emotional language and allow people to talk about their feelings". Shira said that principals must be able to "recognize workers' emotions and encourage talking about emotional situations". Yael added: "School principals have to create times for emotional discussion, to exchange emotional experiences, and to be able to ventilate emotions in open conversation". Sixteen teachers emphasized the importance of preventing criticism and competition.

\section{Promoting Well-being through Professionalism}

Apart from the attributes which teachers related to EI as promoting wellbeing, there where additional reflections and thoughts of 15 teachers who used the term "being professional" as a factor for promoting well-being. For example, Chen, Zahava and Yafit talked about the importance of having a principal with good organizational capabilities. Chen said: "Personal, organizational and authentic skills help principals to lead the school responsibly". Josef fondly speaks about "principals who are perceived as experts, consistent, and authentic" and Merry asserts that being professional means "knowing how to set goals and objectives, to follow through until results are seen, to promote excellent teachers and create a positive feeling".

Another aspect of being professional is the ability to create a professional organizational culture. According to Dekel, "Organizational culture is very 
important and is characterized by work processes, work relations among colleagues, and teaching and learning processes." Dor speaks of "developing norms at school to balance emotions [...] it improves our work and prevents burnout". "A stable and strong working culture will not breakdown the school when a principal leaves work", says Miri. According to Yaffa, "principals should be involved in what goes on at school and not isolate themselves. Personal involvement means to come into classrooms and see first-hand what the challenges are and how teachers handle them".

\section{Discussion}

In this study we aimed to construct new knowledge from Israeli teachers' selfreports regarding the way they perceive the role of school principals as promoting teachers' well-being. Results indicated that school principals play a crucial role in promoting teachers' well-being, as confirmed also by Brotheridge \& Lee (2008).

Teachers' work is considered very stressful (Oplatka, 2017) not only in Israel but also in many places in the world. School life in general can be very stressful (Montgomery \& Rupp, 2005). Stress has been found to negatively affect the wellbeing of individuals and of organizations (O'Driscoll \& Cooper, 1996), while wellbeing has been found to help individuals to cope with stress. As well-being is a combination of feeling good and functioning effectively (Hupper, 2009), school teachers need it, and the principal is a central personality at school who has a great deal of influence on teachers' well-being (Montgomery \& Rupp, 2005). The principal can diminish stress and increase well-being, or vice versa. The planned theory assumed that human behavior is a result of cognitive processes, and the central factor in this theory is the "individual's intention to perform a given behavior that influences a behavior" (Ajzen \& Fishbein, 1980, p.181). According to this theory, the way school principals perceive their role is connected to their attitude, and these connections will affect their behavior. A negative attitude on the part of school principals toward teachers can lead them to negative feelings and to functioning in a way that will create stress (Anary, 2011). On the other hand, a positive outlook will lead to a positive attitude promoting positive behavior. Authentic leadership stems from a more positive psychology of leadership (Seligman, 2002). It consists of integrity and a caring and ethical attitude toward followers (Avolio \& Luthans, 2006). Authentic leadership results in greater selfawareness and self-regulated positive behavior on the part of leaders and associates, fostering positive self-development (Luthans \& Avolio, 2003). These behaviors recognized by Goleman et al. (2004, p. 250) as EI, can make leaders highly effective. As mentioned above, EI contains four clusters which rely on each other. Self-awareness is the basic cluster and after mastering it one can go on to master self-management, following which one can proceed to master the second and third clusters, finally reaching the fourth cluster - relationships management -which is the highest level of EI. Most of the teachers' self-reports as to behaviors promoting well-being related to the relationship management cluster, with 356 statements that comprise all the competencies belonging to this cluster. In the second place were 
the social awareness competencies, the third cluster, with 171 statements that comprise all the competencies belonging to this cluster (Goleman et al., 2004).

\section{Emotional Intelligence Endorses Well-being}

Principals perceptions, attitudes and behaviors reflect their relationship management in their organization. Generating a positive atmosphere, keeping relationships on the right track and preserving an emotionally-healthy school climate all affect teachers' feelings, functioning, and general quality of life, thus promoting their well-being (Barry et al., 2017). School principals' emotions are reflected in the teachers' emotions like in a sort of "emotional tango" between two partners. There is a "ripple effect" of principals' emotions on teachers, and they respond accordingly (Goleman, 2006, p. 136). People respond to negative emotions more strongly than to positive ones, so when principals demonstrate a pleasant attitude, teachers respond positively (Sunindijo, Hardikusumo \& Oguniana, 2007).

EI is about knowing how to manage emotions effectively, allowing people to work together toward common goals. There are two patterns of leadership: resonance and dissonance leadership. Resonance leadership occurs when a leader demonstrates a positive emotional mindset, which brings out the best in people. In dissonance leadership, the opposite occurs, undermining the emotional foundations of the organization. A negative emotion of the principal creates a ripple effect on the teachers and can go as far as affecting the students negatively (Goleman, 2006). Thus, EI is important for improving the well-being of both teachers and students, enhancing their social skills and improving achievements (Ciarrochi \& Mayer, 2007).

\section{Fostering Emotional Climate Improves School's Atmosphere}

Fostering emotional climate produces a positive atmosphere that keeps relationships on the right track. A positive emotional climate is based on a rich emotional vocabulary that helps us to understand other people's emotions and improve communication (Barry et al., 2017; Bracket \& Katulack, 2007). School principals who are more emotionally expressive are more charismatic and more likely to generate a positive emotional climate in the school (Riggio, 2007). Maintaining a positive emotional climate improves mood and health, which also strengthen the immune system (Fredrickson, Mancuso, Branigan, \& Tugade, 2000). Such a positive atmosphere improves critical thinking, creative writing and problem-solving skills, and is extremely important in optimizing effectiveness in multiple domains (Bracket \& Katulack, 2007).

A positive emotional climate allows people to discuss even the most sensitive topics openly with others and with their superiors, and in the school context - with the school principal. Fostering a positive emotional climate promotes teamwork in the organization and satisfies employees' basic need to be involved and committed to their work (Northouse, 2004). "Good communication is an art... Business climate... matters more than ever... [it is] a key factor for enhancing good 
relationships, creating an atmosphere of openness and collaboration, and all of these are products of EI" (Goleman, 2006, p. 9). According to Fullan (2001, p. 51) "If moral purpose is job one, relationships are job two, as you cannot get anywhere without them." The ability to understand the triggers of emotions and to communicate them is essential to the success of all professional and personal relationships (Ciarrochi \& Mayer, 2007). According to Sunindijio et al. (2007), $88 \%$ of project managers spend more than half of their working time interacting with others. Thus, their study concludes: Open communication is a key factor in organizational success as it opens up the possibility of getting the best from people. Creating a positive emotional climate means that leaders care for followers, protect them and treat them fairly. It is a product of how well one understands people and is attuned to their needs (Bradberry \& Greaves, 2005).

\section{Being attuned to Teachers' needs}

School principals who are attuned to teachers' needs contribute positively to the emotional climate of the school as a whole. Teachers' needs encompass a wide range of emotions - both professional and personal. Sometimes listening to a teacher can enhance the emotional climate in the school and create an environment that fosters care and attention (Barcket \& Katulak, 2007). Todd (2003) defined listening as a mode of rationality, which creates the possibility of being open to change and to learning from others. By listening attentively, one can hear more than is being said. This kind of listening is more than a regular dialogue. It enables us to learn from others and to be transformed by this learning. Active listening to subtle communication is a manifestation of being empathetic, which is an integral part of the emotional climate created characteristic of an EI atmosphere (Barcket \& Katulak, 2007). Empathy is our social radar and being empathetic means having the ability to sense and understand what others feel without them having to express their feelings in words, and taking an active interest in their concerns (Goleman, 2006). Covey (2004) explains that whenever we attempt to serve human needs, our relationships improve and deepen.

Teachers' needs are varied and can be pedagogical, technical or personal. Crises at home can easily affect performance at school as recalled by one of the teachers. She recounted a crisis of a homeroom third-grade teacher who had 37 students in her class: "One day two students ran to the principal in the middle of a lesson, telling her that their teacher was crying in class. The principal discovered that the teacher's husband had recently left her. She had no money for psychological assistance and no family to help her, and she was alone with two young children. The principal decided to offer her help from the school psychologist, although the responsibility of the school psychologist is primarily toward the students, or toward teachers in the context of helping them cope more effectively with students. This particular principal understood that by assisting the teacher, she was also helping 37 students and preventing a crisis at school with the students' parents and with the school board in the middle of the year".

Another example relates to a new law that was recently been passed in Israel, allowing students with special needs to attend regular classes instead of learning in 
special education classes, and not having special assistance during all school hours. One of the teachers described her frustration at not being able to teach, after investing long hours of preparation in a special lesson aimed at arousing her students' interest and curiosity, because of an unexpected situation with a specialneeds student in her class. She described her students' and her own frustration at not being assisted by anyone at the school, which to her felt like a situation that could totally diminish her well-being. Another example related to a technical problem that a teacher had with a computer projector which stopped working. These situations were all frustrating and stressful for teachers and students alike, and an ounce of help at the right moment could have reduced their frustration.

Another issue that school principals must be aware of is the conflict between home and school demands. A recent study published in Israel on the conflict between school and home demands (Buskila \& Chen Levi, 2020) has shown that teachers who feel that their school principals are attuned to their needs and care to prevent this situation will get much more from teachers, which will in turn benefit the school. Being attuned to teachers' needs reduces pressure, stress and chaos, and results in improved teacher well-being, which enables students to benefit from a relaxed teacher. People who are threatened or uncertain physically, socially or emotionally are unlikely to be able to participate fully in learning or working processes (Allen \& Cohen, 2006). Physical needs range from having an orderly and clean space in which one can work, and feeling safe, i.e., unthreatened by any form of bodily harm both at school and in the community. Thus, creating an emotional climate that enables teachers not to feel alone with their problems is valuable. Sometimes the solution for a certain problem may come from another teacher with a helpful idea; sometimes providing a substitute teacher to replace a tired teacher in the classroom, or talking things over to clarify a misunderstanding, or just allowing a teacher to rest and calm down - prove to be significantly helpful.

\section{Practical and Theoretical Implications}

The Israeli education system is stressful for many reasons, including large class sizes, up to as many as 40 students per class. Recent reforms have created greater accountability but have also added a huge bureaucratic burden of forms to be filled out by teachers. This situation has had negative consequences for both teachers and principals (Berkovich \& Eyal, 2016; Schechter, 2015). It is thus advisable for school principals to be more aware of the fact that teachers' wellbeing fosters professional effectiveness, helping individuals to cope with stress, work productively, and contribute to the school and to the community. School principals will do well to grow more aware of the significance of EI, which can make them more highly effective as leaders and assist them in promoting teachers' well-being (Barry et al., 2017; Goleman et al., 2004). Moreover, if school principals and policy-makers try to diminish teachers' stress and provide them with more assistance, they will most likely promote their well-being. Universities, colleges and staff development trainers may benefit from including EI curriculum and well-being curriculum in educational leaders' training. 


\section{Limitations of the Study and Suggestions for Further Research}

The small size of our sample - 53 participants - may be one of the limitations of this study. A small sample can affect the feasibility of generalizing findings (Crotty, 2005). There is an inherent challenge in conducting research on a broad topic such as teachers' perceptions about their own well-being. Another limitation pertains to the fact that the research has been done in Israel and therefore its results may have been affected by the Israeli culture, including its organizational and managerial characteristics. Additional implications are related to the fact that the self-reports have been given by teachers from public schools, thus our findings and results may not be relevant to private schools or to other sorts of schools with different cultures and ideologies in Israel.

This study illustrates the need for further research concerning the promotion of teachers' well-being by school principals from the school principals' viewpoint. Similar cross-cultural studies from other countries should address this theme in order to provide a cross-cultural perspective.

\section{References}

Ajzen, I. (1991). The theory of planned behavior. Organizational behavior and human decision processes, 50, $179-2011$.

Ajzen, I., \& Fishbein, M. (1980). Understanding attitude and predicting social behavior. Englewood Cliffs, NJ: Prentice-Hall.

Allen, J., \& Cohen, J. (2006). Emotional intelligence in classrooms and in schools: What we see in the educational setting. In K. R. Murphy (Eds.). In K. R. Murphy (Eds.), A critique of emotional intelligence, (p.p. 125 - 139). Pennsylvania State University.

Anari, N. N. (2011). Teachers: emotional intelligence, job satisfaction and organizational commitment. Journal of Workplace Learning, 24, 259 - 269.

Avolio B. J. \& Gardner, W. L. (2005). Authentic leadership development: Getting to the root of positive forms of leadership. Leadership Quarterly, 16: 315 - 338.

Avolio B. J. \& Luthans, F. (2006). The high impact leader: Authentic, resilient leadership that gets results and sustains growth. New York: McGraw-Hill.

Ashkanasy, N. M., \& Dorris, A. D. (2017). Emotions in the workplace. Annual Review of Organizational Behavior, 4, 67 - 90 .

Barry, M. M., Clarke, A. M. \& Dowling, K. (2017). Promoting social and emotional wellbeing in schools. Health Education, 117 (5), 434 - 451.

Bas, G. (2011). Teacher student control ideology and burnout: Their correlation. Australian. Journal of Teacher Education, 36(4) 6, 84 - 94.

Bass, B.M. \& Avolio, B.J. (1994). Improving Organizational Effectiveness through Transformational Leadership, Sage, Thousand Oaks, CA.

Begleym P. T., \& Stefkovich, J. (2007). Integrating values and ethics into post-secondary for teacher development: Principals, concepts and strategies. Journal of Educational Administration, 45, 398 - 423.

Bellingrath, S., Weigl, T., \& Kudielka, B. M. (2008). Chronic work stress and exhaustion in associated with higher allostatic load in female school teachers. Stress, 12(1), 3748.

Berkovitch, I. (2014). Neo-liberal governance and the new professionalism of Israeli principals. Comparative Education Review, 58(3) 428 - 456. 
Berkovich, I. \& Eyal, O. (2017). The mediating role of principals' transformational leadership behaviors in promoting teachers' emotional wellness at work: a study in Israeli primary schools. Educational Management Administration \& Leadership, $45(2), 316-335$.

Berkovich, I. \& Eyal, O. (2016). Emotional reframing as a mediator of the relationships between transformations school leadership and teachers' motivation and commitment. Journal of educational Administration, 55 (5) 450 - 468.

Bird, J. J., Wang, C., Watson, J., \& Murray, L. (2009). Relationships among principal's authentic leadership, teacher trusts and engagement levels, Journal of School Leadership, 19, 153 - 171.

Bogler, R., \& Nir., A. (2014). The contribution of perceived fit between job demands and abilities to teaches' commitment ad jo satisfaction. Educational Management Administration and Leadership, 43(4), 541 - 560.

Brotherige, C. M., \& Lee, R.T. (2008). The emotions of managing: An introduction to the special issue. Journal of Managerial Psychology, 23 (2) 108 - 117.

Brackett, M. A. \& Katulal, N. A. (2007). Emotional Intelligence in the classroom: skillBased Training for teachers and students. In J. Ciarochi \& J. D. Mayer (Eds.), Applying Emotional Cognition (pp 1 - 27). NY: John Psychology Press Taylor \& Francis Group.

Buskila, Y., \& Chen Levi, T. (2020). Teachers without air: Mapping the stress causes of Israeli teachers in their work. Gilui Daat.(Hebrew).

Bradbarry, T. \& Greaves, J. (2005). The emotional intelligence quick book. New York: Fireside.

Carnoy, Martin, (1995). Structural adjustment and the changing face of education. International Labor Review, 134(6), 653 - 673.

Cherniss, C. (1980). Professional burnout in human service organizations. New York: Praeger

Ciarrochi, J. \& Mayer, J. D. (2007), Introduction. Applying emotional intelligence. New York, Psychology press. p. XII.

Clarke, C., Hype-Hailey, V., \&Kellinher, C. (2007). Being real or really being someone else? Change, managers and emotion work. European Management Journal, 25 (2) $93-103$.

Cliffe, J. (2011). Emotional Intelligence: A study of female secondary school head subordinates. Educational Management Administration and Leadership 39(2): 205 2018.

Covey, R. S. (2004). The $8^{\text {th }}$ habit: from effectiveness to greatness. New York: Free press.

Crotty, M (2003). The Foundations of social research: Meaning and perspective in the research process. Thousand Oaks, Ca, Sage.

Detal Lior, (May 6, 19). Auditor's Report: How to Raise a Lost Generation: Shortage of 3000 Teachers while those teaching are unqualified. Retrieved at 2.12.19 from https://www.themarker.com/news/בeducation/1.7206718

Durlak, J. A., Weisberg, R. P., Dymnici, A. B., Tailore R. D. and Schellinger K. B. (2011). The impact of enhancing students' social and emotional learning: a meta-analysis of school based universal intervention. Child Development, Vol, 82, 1, 204 - 432.

Fullan, M. (1998). Leadership for the $21^{\text {st }}$ century: Breaking the bonds of dependency. Educational Leadership, 55 (7), 45 - 51.

Fullan, M. (2001). Leading changes in a culture of change, 51 - 76. Sun Francisco, JossayBass.

Forgas, J.P. (2006). Affective influences on interpersonal behavior: Towards understanding the role of affect in everyday interactions. In J.P. Forgas (Ed.), Affect in social thinking and behavior (pp. 269-290). New York: Psychology Press. 
Friedman, I., Kemper, C., (1994). Preparations for treatment and relief of stress and burnout in teaching. Jerusalem: Henrietta Szold Institute. (Hebrew).

Fredrickson, B.L., Mancuso, R.A., Branigan, C., \& Tugade, M. (2000). The undoing effect of positive emotions. Motivation and Emotion, 24, 237-258.

George, J.M. (2000), "Emotions and leadership: the role of emotional intelligence", Human Relations, Vol. 53, pp. 1027-55.

Goleman, D. (2006). Working with emotional intelligence. New York: Bantam books

Goleman, D., Boyatzis, R., \& McKee, A. (2004). Primal leadership: realizing a power of emotional intelligence. Boston, Massachusetts: Harvard Business School Press.

Grissom, J. A., Loeb, \& S. \& Mitani, H. (2013). Principal time management skills: explaining patterns in principals' time use and effectiveness Stanford University: Center for Education Policy.

Hakanen, J. J., Bakker, A. B., \& Schaufeli, W. B. (2006). Burnout and work engagement among teachers, Journal of School Psychology, 43, 495 - 513.

Harris, L. C. (2002). The emotional labor of barristers: An exploration of emotional labor by status professionals. Journal of Management Studies, 39 (4) 553 - 584.

Huppert, F. A. (2009). Psychological well-being: evidence regarding its cause and consequences. Applied Psychology: Health and well-Being. 1. (2). 137 - 164.

Hung, S.L., Li, R.H., Fang, S.Y., \&Tang, F.C. (2019). Well-being: Its relationship with work to family conflict and burnout among males and femals. Public Health, 16(13), 2291. Retrieved from: https://www.mdpi.com/1660-4601/16/13/2291/htm

Jackson, S. E., Schwab, R, L, \& Schuler (1986). Toward and understanding the burnout phenomenon. Journal of Applied Psychology, 71, 639 - 640.

James, C. \& Vince, R. (2001). Developing the leadership capability of headteachers, Educational Management, Administration \& Leadership, 29(3), 307 - 317.

Jepson, E. \& Forrest, S. (2006). Individual contributory factors in teachers stress: The role of achievement striving and occupational commitment. British Journal of Educational Psychology, 76, 183 - 197

Keer, R., Garvin, J., Heaton, N., \& Boyle. R. (2005). Emotional intelligence and leadership effectiveness School. EI and leadership effectiveness. Pp. 265 - 278. Retried from: www.emeraldinsight.com/0143-7739.htm

Kyriacou, C. (2001). Teacher stress: Directions for future research. Educational Review, 53 (1) $27-35$.

Leory, H., Palanski, M. E., \& Simons, T. (2011). Authentic leadership and behavioral integrity as drivers of follower commitment and performance. Journal of Business Ethics. Advanced online publication. Doi:10.1007/s10551-011-1036-1

Luthans, F. \& Avolio, B.J. (2003). Authentic leadership development. In K. S. Camron, J. E. Duttton, \& R. E. Quin (Eds.), Positive organizational scholarship: 241 - 258. San Francisco: Berrett-Koehler.

Merriam, S. B. (2009). Qualitative Research: A guide to design and implementation. San Francisco: Jossey-Bass.

Montgomery, C. \& Rupp, A. A. (2005). A Meta-analysis for exploring the diverse causes and effects of stress in teachers. Canadian Journal of Education. 29(3) 458 - 486.

Niessen, Mader, Stride \&Jimmieson, (2017). Thriving when exhausted: The role of perceived transformational leadership. Journal of Vocational Behavior. 103(2017) 41 -51 .

Northouse, P. G. (2004). Leadership theory and practice, India: Sage publication.

O'Driscoll, M. P., \& Cooper, C. L. (1996). Source and management of excessive job stress and burnout. In P. Warr (Ed.). Psychology at Work (4 ${ }^{\text {th }}$ ed.) $182-223$. Penguin Books: London. 
Oplatka, I. (2017). A new look on OfekChadash (The New Horizon) reform, HedHachinuch, 5, 98 - 99. (Hebrew).

Oplatka, I. (2011). The dynamic nature of emotions in the educational leadership: Lessons from the career stories of Israeli late career principals. In Day C. Chic Lee J. (eds). New understanding of teachers works. Dordrecht, Netherlands: Springe. 187 - 204.

Riggio, R. E. (2007). The Emotional and social intelligences of effective leadership: An emotional and social skill approach. Journal of managerial Psychology, 23(2), 341 360.

Salovey, P. and Mayer, J. (1990), "Emotional intelligence", Imagination, Cognition, and Personality, Vol. 9 No. 3, pp. 185-211.

Schecter, C. (2015). Let Us lead! School principals at the forefront of reforms. Tel Aviv: Ramot publications, Tel Aviv University. (Hebrew).

Seligman, M. E. P. (2002. Authentic happiness: Using the new positive psychology to realize your potential for lasting fulfillment. New York: Free Press.

Shapira- Lishchinski, O. \& Tzemach, S. (2014). Psychological empowerment as a mediator between teachers' perceptions of authentic leadership and their withdrawal and citizenship behavior. Educational Administration quarterly. 1 - 38 .

Schneider-Levy, L. (2016). Impact of Inquiry Based Stress Reduction (IBSR) on teacher burnout and mental well-being. (PhD dissertation) Tel Aviv University. (Hebrew).

Sunindijo, R. S., \& Hardikusumo, B. H. Y., \& Oguniana, S. (2007). Journal of Management in Engineering, 23 (4), 166 - 170.

Todd, S. (2003). Learning from others, New York: university of New York Press.

World Health Organization (2001). The world health report-mental health: New understanding, new hope. Geneva: World Health Organization. 